\title{
Overweight and diabetes prevention: is a low-carbohydrate-high-fat diet recommendable?
}

\author{
Fred Brouns ${ }^{1}$ (1)
}

Received: 10 July 2017 / Accepted: 12 February 2018 / Published online: 14 March 2018

(c) The Author(s) 2018. This article is an open access publication

\begin{abstract}
In the past, different types of diet with a generally low-carbohydrate content $(<50-<20 \mathrm{~g} / \mathrm{day})$ have been promoted, for weight loss and diabetes, and the effectiveness of a very low dietary carbohydrate content has always been a matter of debate. A significant reduction in the amount of carbohydrates in the diet is usually accompanied by an increase in the amount of fat and to a lesser extent, also protein. Accordingly, using the term "low carb-high fat" (LCHF) diet is most appropriate. Low/very low intakes of carbohydrate food sources may impact on overall diet quality and long-term effects of such drastic diet changes remain at present unknown. This narrative review highlights recent metabolic and clinical outcomes of studies as well as practical feasibility of low LCHF diets. A few relevant observations are as follows: (1) any diet type resulting in reduced energy intake will result in weight loss and related favorable metabolic and functional changes; (2) short-term LCHF studies show both favorable and less desirable effects; (3) sustained adherence to a ketogenic LCHF diet appears to be difficult. A non-ketogenic diet supplying 100-150 g carbohydrate/day, under good control, may be more practical. (4) There is lack of data supporting long-term efficacy, safety and health benefits of LCHF diets. Any recommendation should be judged in this light. (5) Lifestyle intervention in people at high risk of developing type 2 diabetes, while maintaining a relative carbohydrate-rich diet, results in long-term prevention of progression to type 2 diabetes and is generally seen as safe.
\end{abstract}

Keywords Low-carbohydrate diet · High-fat diet · Ketogenic diet · Type 2 diabetes · Obesity.

\section{Introduction}

The World Health Organisation (WHO) and various national authorities have recently made recommendations urging a limitation of the daily consumption of carbohydrates, more specifically that of rapidly digestible starches and sugars. These recommendations play a key role in reducing the risks of obesity, diabetes, and cardiovascular diseases [1-8]. In the past, there have been various diets that centre on a lowcarbohydrate content, such as the Atkins Diet, the Zone Diet, the South Beach Diet and the ketogenic diet [9-13].

In this respect, it should be pointed out that although many studies refer explicitely to "diets with a low-carbohydrate

Fred Brouns

fred.brouns@maastrichtuniversity.nl

1 Department of Human biology, Faculty of Health, Medicine and Life Sciences, NUTRIM-School of Nutrition and Translational Research in Metabolism, Maastricht University, Post Box 616, 6200 MD Maastricht, The Netherlands content", this in fact goes hand in hand with "elevated fat". This well-known "seesaw effect" is present in many nutritional intervention studies in which a decrease of one particular component always is accompanied by a parallel increase of another component. In other words, effects observed are then based on two dietary factors that were changed in parallel and any conclusion drawn should be viewed in this light. Accordingly the term "low carbohydrate-high fat diet" (LCHF diet) is more appropriate than "low carbohydrate" alone, also in terms of interpretation of results. For this reason, the term LCHF will be used throughout this paper.

Feinman et al. [14] proposed that dietary carbohydrate restriction is the first approach in diabetes management, the authors refer to much data showing that favorable effects such as improvement of insulin sensitivity/needs occurred along with significant weight loss. However, many of the cited studies concerned relatively small groups of individuals, often with poor diet adherence and relatively high dropout rates. Accordingly, one may question the validity of their proposal, especially since recent meta-analyses, which 
did include well-controlled studies did not see beneficial changes in many parameters on the longer term (this will be discussed further in detail below). Important questions that ought to be put in this respect include: (a) what are the real long-term effects of very low-carbohydrate, thus high-fat intake; (b) are the effects observed rather the result of weight loss than of low carbohydrate per se, and (c) are there less drastic alternatives, i.e. more moderate changes of carbohydrate and fat intake that are easier to adhere to and lead to similar favorable results. These questions are also relevant, given that most chronic diseases such as diabetes, cardiovascular diseases and other chronic conditions have a development period of 10-20 years or more. Long-term data, demonstrating favorable effects of a (very) LCHF diet in this regard, is absent. In addition, there is also a plethora of studies that show that maintaining a relatively high-carbohydrate, low-glycemic-high-fiber diet (vegetarian, vegan) results in favorable long-term effects. Such diet patterns deviate less drastically from our normal eating patterns and are easier to implement in the long term [15-21]. In this respect, observations made in the so-called "blue zones", e.g. Sardinia, Okinawa (Japan), Loma-Linda (California), are intriguing, given their commonality is their relatively high-carbohydrate and low-saturated fat content of their daily diet, which allow them to stay healthy until very high age. The Okinawa inhabitants, for example, originally ate a daily diet that contained an amount of carbohydrates that exceeded daily energy intake by $60 \%$, consisting primarily of sweet potatoes and the foliage, supplemented with seaweed and fruit. The recent introduction of a more Western lifestyle, containing more saturated fats, added sugars and alcohol, has gone to the significant detriment of the longevity prospects of the youngest generation [22], which indicates that diet (carbohydrate and fat quality), in combination with other lifestyle factors is crucial for health.

An important question is why a challenging LCHF diet, with risks of poor adherence, should be implemented when less drastic changes in diet and lifestyle have proven effects and are known to be safe and easier to follow on the long run. Opinions seem to be sharply divided on the matter. This narrative review will shine a light on the various international opinions on the matter.

\section{Is a high carbohydrate content of the diet unhealthy?}

There are various publications that assert that high levels of carbohydrates are unhealthy. The arguments to support this are often based on assumptions on how man was to have eaten long ago, before the agricultural and industrial revolution. This is referred to as the Paleo Diet. Some authors explicitly claim that our ancestors ate a diet high in fat and protein and that starches and cereals were not part of the daily diet [23]. Historical data available to us, however, have shown that the diet 50,000 years ago, in fact, was relatively high in carbohydrates, that it contained a high level of fiber (from plant-based foods) and that the level of fats primarily depended on the fat content of the various types of meat and fish available [24]. The Paleo diet contained an estimate of $\approx 35$ percent of energy (en $\%$ ) from fats, $\approx 35$ en $\%$ from carbohydrates and $\approx 30 \mathrm{en} \%$ from proteins, with approx. $100 \mathrm{~g}$ of dietary fiber a day [24-26]. Consequently, in quantitative terms, the Paleo diet contained roughly as much fat as does our modern Western diet. Observations made by Kaplan et al. [27] who studied the Tsimane population in South America are of great interest in this respect. This population lives a traditional hunter-gatherer lifestyle and ingests an estimated $14 \%$ of their average caloric diet as protein, $14 \%$ as fat, and $72 \%$ as carbohydrate. Yet, despite this very high-carbohydrate intake, the Tsimane have the lowest reported levels of chronic disease of any population ever recorded to date! Today, there are no arguments to suggest that the diet of our ancestors was low in carbohydrate. Quality but not quantity of carbohydrates appears to be a key aspect to be considered.

\section{What does "low carbohydrate" and "ketogenic" refer to?}

A large number of publications refer to a diet "low in carbohydrates" or to "ketogenic". But what levels of carbohydrate correspond to these concepts? We could start by assuming that low refers to lower than the current average intake or lower than current recommendations. According to the most recent Dutch Food Consumption Survey (FCS, 2007-2010; 7-69 years), the average daily intake of macronutrients is $45 \mathrm{en} \%$ from carbohydrates (of which $21 \mathrm{en} \%$ from sugars and $24 \mathrm{en} \%$ from starch), $35 \mathrm{en} \%$ from fats, 15 en\% from protein and 15-23 g of fiber [28]. On that basis, the term "low" could refer to lower than 45 en\% derived from carbohydrates. However, does that necessarily mean low in terms of the effects on our metabolism? Currently, only guidelines exist regarding the recommended daily intake of foods and there are no international guidelines on high- or low-limit values. Anything above or below the recommended intake amounts can, respectively, be referred to as high or low. Therefore, the question is which bandwidth is defined as 'low carbohydrate' when comparing studies to one another to draw conclusions regarding the effects. Westman [29] describes this problem as follows: "Much of the controversy when studying the outcomes of LCHF diets stems from the lack of a clear definition. The guiding principle of carbohydrate limitation is that, in response to the reduced availability of glucose and lower insulin values 
in the blood, the body should enter a state of increased fat burning, leading to ketosis. It would appear that a type of threshold value for carbohydrate intake exists above which this metabolic change does not clearly occur. For that reason, ketogenic studies are interpreted assuming only $20-50 \mathrm{~g}$ of carbohydrates per day and, if possible, a maximum of $20 \mathrm{~g}$ per day $[29,30]$. Fewer ketone bodies are formed in the liver upon intake of more carbohydrates. In such cases, the term used is a low-carbohydrate diet rather than a ketogenic diet, the former containing 50 to max. $150 \mathrm{~g}$ of carbohydrates per day".

\section{What are the metabolic effects of a low-carbohydrate availability?}

Two processes that come into play when glucose availability is in decline: (1) gluconeogenesis, (2) ketogenesis. Below these aspects will be explained in short.

\section{Gluconeogenesis}

A very low-carbohydrate intake ( $<50 \mathrm{~g}$ per day) will result in a decreasing glucose supply to the liver, muscles and brain, resulting in a decline in the amount of glucose stored as glycogen. When glucose availability is limiting the body will activate a process called gluconeogenesis. Gluconeogenesis (endogenous production of glucose) and glycolysis (breakdown of glucose) are processes that always take place simultaneously and are reciprocal (if one is high, the other is low, and vice versa). The primary carbon skeletons required for the synthesis of glucose in gluconeogenesis (Fig. 1) come from lactic acid, glycerol and the amino acids alanine and glutamine [31].

\section{Ketogenesis}

When endogenous production of glucose by gluconeogenesis remains too low to cover the body's glucose needs of cells that primarily rely on glucose as a fuel, ketone bodies will be produced as an alternative to glucose [32]. In this condition, insulin levels in the blood will be low, sharply reducing the stimulus for fat and glucose storage. This observation is often referred to when promoting a high fat diet for weight maintenance and reduction of diabetes risk factors (see also further below). Other hormonal changes would subsequently lead to an increase in the breakdown of fat from the fat cells and making more fatty acids available as fuel. In this situation of a continuous elevated supply of fatty acids, not all fatty acids will be burnt completely. Acetoacetic acid (acetoacetate) is then created which is subsequently converted

\section{Gluconeogenesis:}

Synthesis of glucose in the liver from "non-carbohydrates"

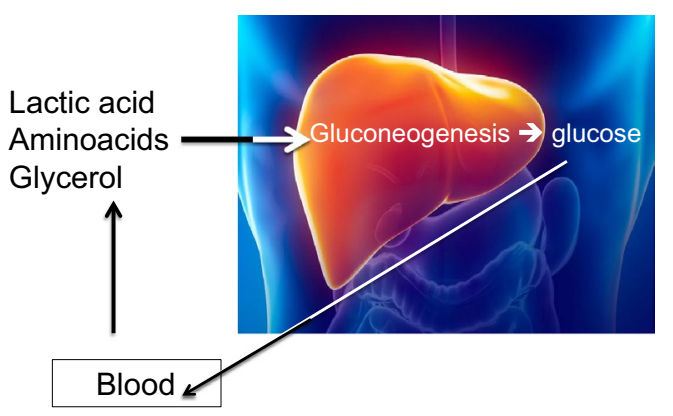

Fig. 1 Gluconeogenesis (production of glucose) and glycolysis (breakdown of glucose) are processes that always take place simultaneously and are reciprocal (if one is high, the other is low, and vice versa). In cases of low-glucose availability from glycogen, glycolysis will be conducted at a low level and there will be a stimulus for gluconeogenesis

into the ketones beta-hydroxybutyric acid ( $\beta$-hydroxybutyric acid) and acetone. For that reason, ketones are to be regarded as "a type of emergency generator that kicks in when there is a power outage". Figures 2, 3, 4 and 5 give a schematic representation of the metabolic processes in case of a normal carbohydrate intake and after limitation of carbohydrate intake leading to ketosis.

\section{Do frequent carbohydrate-induced insulin responses drive overweight?}

According to Hall [32], the carbohydrate-insulin model of obesity theorizes that diets high in carbohydrate are particularly fattening due to their propensity to elevate insulin secretion. Insulin directs the partitioning of energy toward storage as fat in adipose tissue and away from oxidation by metabolically active tissues and purportedly results in a perceived state of cellular internal starvation. In response, hunger and appetite increases and metabolism is suppressed, thereby promoting the positive energy balance associated with the development of obesity. Hall states that this hypothesis, which is cited by many to support recommendations for a LCHF diet, cannot be verified by controlled studies. He also suggests that the mechanisms most likely are far more complex than previously thought, given that the differences in energy consumption and body fat, as observed in the controlled case studies, are contrary to the differences that are predicted based on the carbohydrate-insulin model. Hall claims that although the rise of the prevalence of obesity may be put down to elevated consumption of refined carbohydrates, the mechanisms are most likely completely different from what we think 
Fig. 2 In a high-carbohydrate diet, the glucose reserves in the liver and muscles are usually well stocked. In fasting conditions, blood glucose levels are kept steady by breakdown of glucose from the liver glycogen. This is regulated by the insulin/ glucagon ratio. The low insulin levels ensure that relatively few fatty acids are stored in the adipose cells, while the secretion of fatty acids by the breakdown of stored lipid (lipolysis) ensures elevated blood plasma fatty acid levels. This leads to a high degree of fatty acids oxidation and relatively low oxidation of glucose. This is then expressed in a low respiratory quotient (RQ), usually $0.75-0.8$
Fasted energy metabolism, while being on a carbohydrate rich diet**

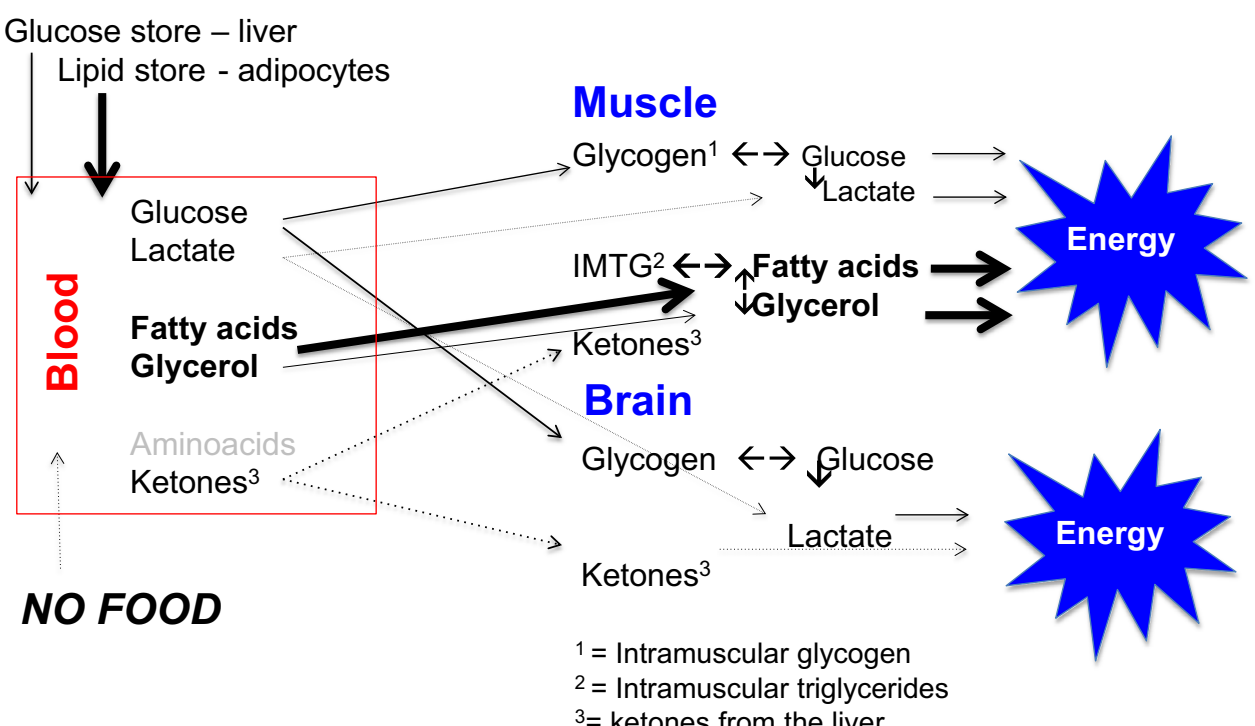

Energy metabolism after a meal, while being on a carbohydrate rich diet

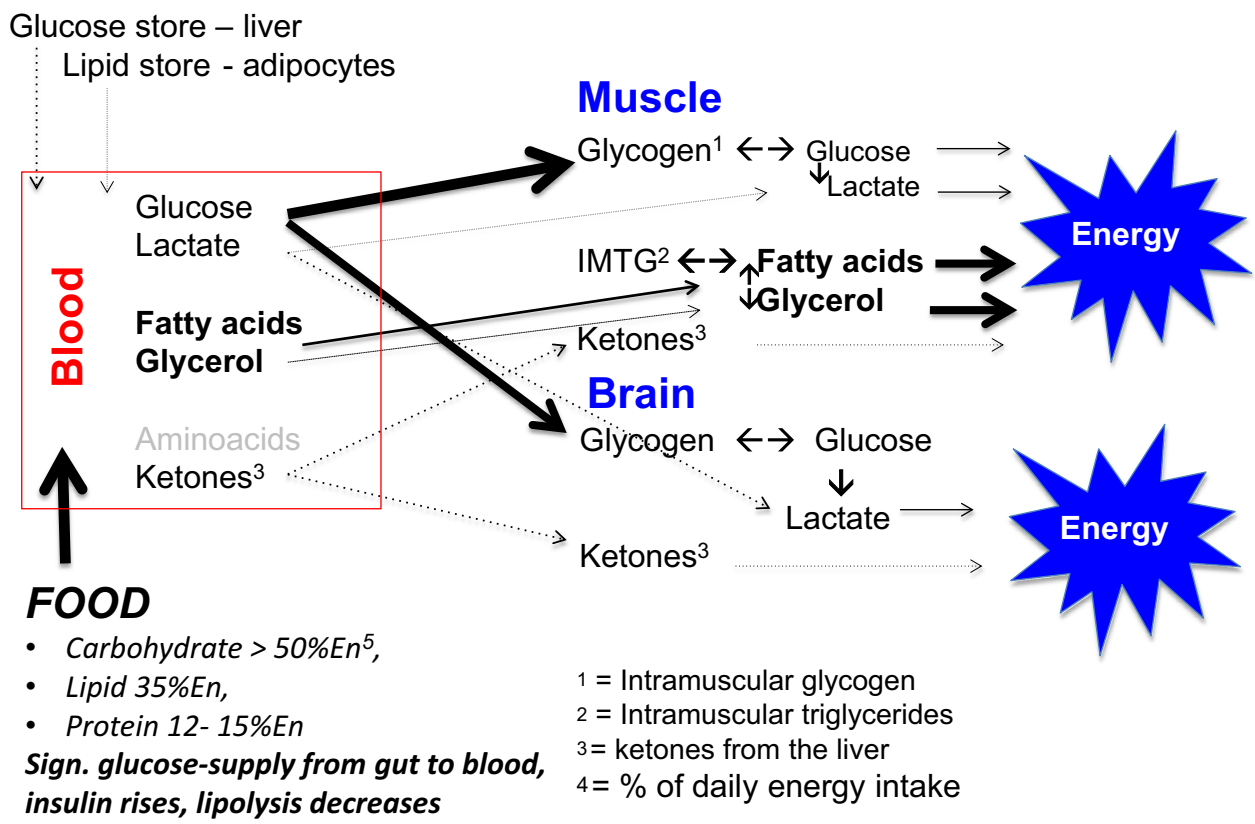

Fig. 3 Following a carbohydrate-rich meal, the blood glucose is elevated by the supply of glucose from the intestine, resulting in elevated insulin levels and a temporary decrease in glucagon levels. This combination results in a sharp decrease in glucose production from the liver glycogen. At the same time, the release of fatty acids from the adipose cells is inhibited and the uptake of both glucose and fatty acids from the blood is stimulated. In this case, the burning of primarily fatty acids in a fasting condition shifts to a combination of elevated glucose- and reduced fat oxidation. This is expressed in an elevated respiratory quotient (RQ), depending on the carbohydrate intake and the magnitude of the insulin response, between 0.85 and 1.0. There is also a small contribution from amino acids, which are converted into glucose via gluconeogenesis. Under normal conditions, this amounts to approx. 1-3\%, although in cases of acute or chronic carbohydrate restriction resulting in significant glycogen breakdown and depending on the degree of adaptation to the situation this can even rise to $>15 \%$ [32-37]

level of added sugars could result in a greater total energy 


\section{Energy metabolism during a high Fat -low Carb diet}

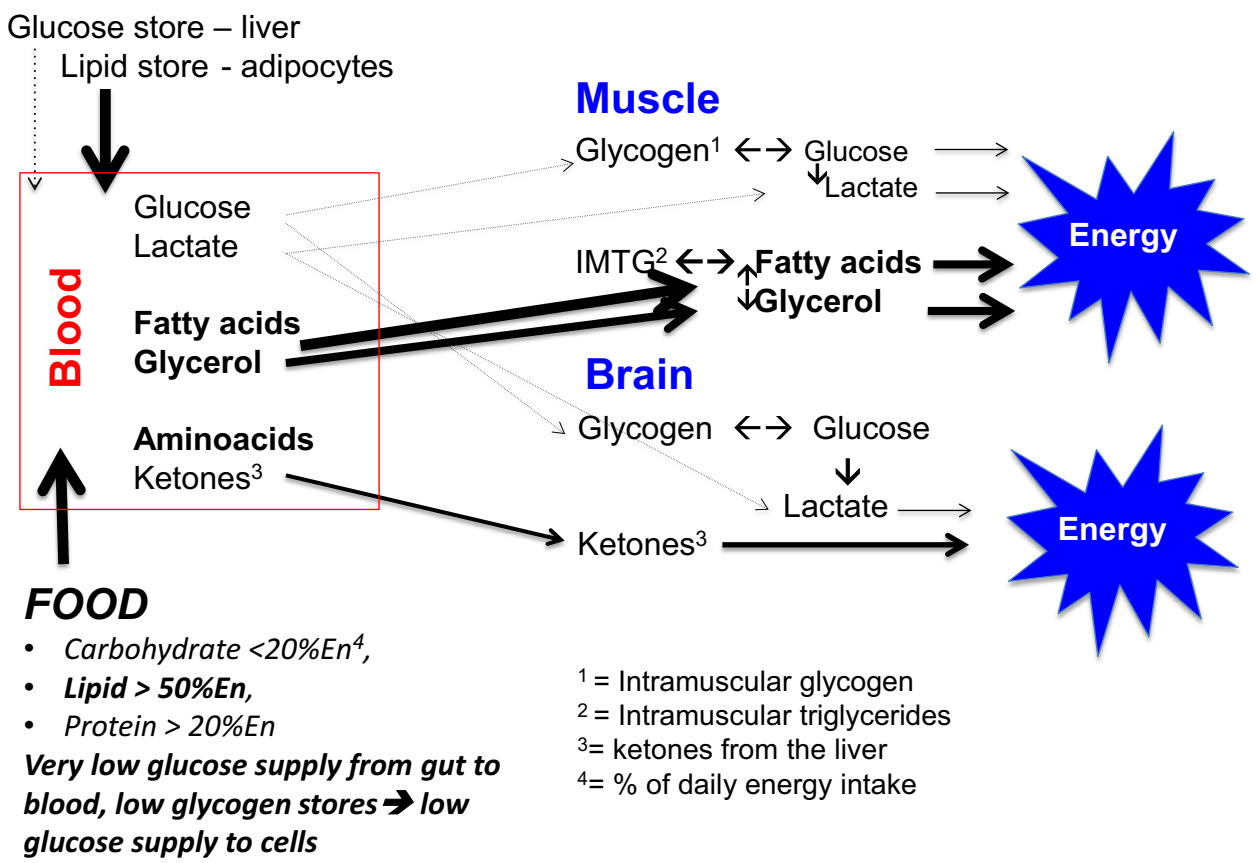

Fig. 4 When following an LCHF diet, the amount of glucose that is taken up in the blood from the food each day is insufficient to maintain the glycogen stores in the liver and muscles. This results in an reduction of glycogen stores, reduced glucose release and consequently to reduced blood glucose levels. The body experiences this as stress and will do everything it can to ensure it burns fatty acids as much as possible with the aim of preventing utilization of glucose, which is needed primarily for the central nervous system and the red blood cells, as much as possible. This is achieved by a sharp decrease in insulin and an increase of stress hormones. This results in an excess supply of fatty acids, leading to a partially incomplete metabolism in which ketones are produced (ketogenesis) from a part of the produced acetyl-CoA. These ketones can then be used by the brain and the muscles as an alternative fuel source instead of glucose. This is crucial to the brain, as fatty acids cannot pass through the blood-brain barrier, while glucose and ketones can. In the case of a shortage of glucose, the brain cells and neurons are able to use ketones as an alternative fuel source. There is also a small to medium contribution from amino acids, which are converted into glucose via gluconeogenesis
Fig. 5 Ketogenesis is a process that takes place entirely in the liver

\section{Ketogenesis and ketosis}
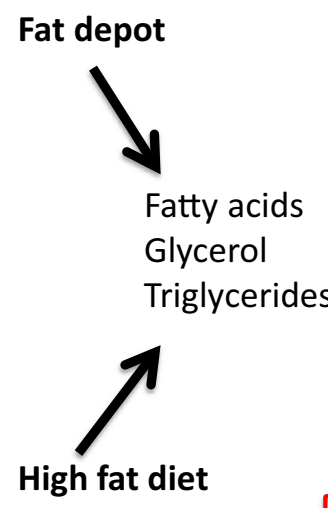

High fat diet

Fatty acids

Glycerol Triglycerides

ketogenesis

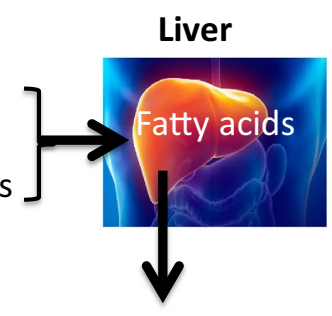

Acyl CoA Acetyl CoA $\beta$-oxidation Acetoacetyl CoA HMG CoA ) Acetoacetate 3-OH-butyrate
Muscle, Brain

Glucose
Pyruvic acid

If

Acetyl coA

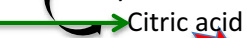

Oxalic acid

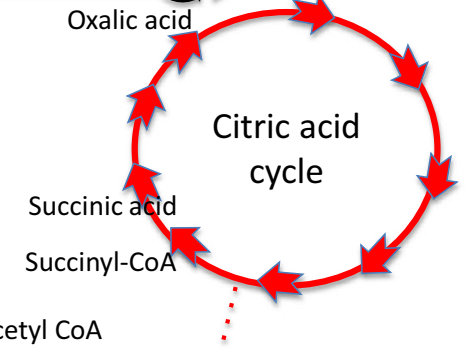


intake because they have a more attractive taste, stimulate to eat more or reduce satiety. Most recently, Hall and Guo postulated that while low-carbohydrate diets have been suggested to partially subvert these processes by increasing energy expenditure and promoting fat loss, their metaanalysis of 32 controlled feeding studies, with isocaloric substitution of carbohydrate for fat, found that both energy expenditure (26 kcal/day; $P<0.0001)$ and fat loss $(16 \mathrm{~g} /$ day; $P<0.0001)$ were greater with lower fat diets [38].

\section{Does LCHF diet improve insulin action?}

The scientific literature shows that individuals suffering from pre-diabetes (as shown by fasting glucose and insulin levels) or suffering from diabetes and who switch to a LCHF diet soon notice a number of effects, such as weight loss, improved insulin sensitivity, fewer fluctuations in blood glucose levels and lower fasting blood glucose levels. Such changes indirectly entail reduced risks of cardiovascular diseases [13, 14, 39]. However, there are also scientists that consider these effects primarily to be the results of weight loss and not necessarily the result of a reduction in carbohydrate intake itself. Westman et al. [29] published a thematic review of the metabolic effects of LCHF diets, and concluded that LCHF diets lead to reduction of appetite and, consequently, to weight loss and corresponding improvements of various disease risk factors.

\section{Does LCHF reduce dietary fiber intake?}

In general, most natural carbohydrate-rich food sources are high in dietary fibers and micronutrients. For that reason, the key question arises whether switching to a LCHF diet would not lead to a significant decrease in the supply fiber, known to impact negatively on gut function and overall health [40]. A study that conducted an accurate analysis of this issue and of the relationship between popular diets and food quality (expressed as a food index score) showed that diets with less than 30 en\% carbohydrates ended up in the lowest index score [41, 42], indicating that there is a realistic risk of low fiber and micronutrient intakes when consuming an LCHF diet.

Based on various meta-analysis, an appropriate dietary fiber intake, for example by consuming more whole grain compared to a low intake of whole grain, is linked to a significant disease risk reductions for diabetes type 2 , cardiovascular disease [43, 44], while evidence is growing that weight management may also be supported favorably $[45,46]$. The fact that LCHF diets may reduce diet quality is of concern and indicates a need for carefull nutritional guidance when following such diets.

\section{What do meta-analyses of LCHF diets tell us?}

Astrup et al. [47] initially set out to study the effects of a high-carbohydrate diet, relatively low in fat low-fat. They asserted that the effectiveness of an ad libitum diet, relatively high in carbohydrate, as was often recommended for the prevention of weight gain in patients with normal weight, or a decrease in body weight in the case of obesity, was controversial. This resulted in a meta-analysis into the effects of intervention studies which included studies in which non-diabetic individuals consumed a low-fat (thus, consequently, a relatively carbohydrate-rich) diet, a normal diet, or a diet moderately rich in fat (control group). Following a stringent selection process, the details of 16 studies were evaluated (duration of 2-12 months, 19 intervention groups, 1910 people). At the inception of the studies, the average fat consumption of the persons in the low-fat group was $37.7 \%$ (95\% Cl 36.9-38.5). In the control group, this was $37.4 \%$ (36.4-38.4). Consequently, fat consumption was equal in both the low-fat and control groups. The low-fat intervention reduced fat intake in the low-fat test groups to $10.2 \%(8.1-12.3)$ while fat intake remained unchanged in the control groups. The data showed that the energy intake of the LFHC intervention groups was lower $(1138 \mathrm{~kJ} /$ day, $P<00.002)$ and that they showed more weight loss than the control groups $(3.2 \mathrm{~kg}, \mathrm{Cl} 1.9-4.5 \mathrm{~kg}, P<0.0001)$. The authors concluded that a reduction of the fat content in the diet, without targeted restriction of the energy intake, resulted in higher weight loss, especially in persons with the highest body weight. The foregoing corresponds to the considerations put forward by Hall et al. [48] in a publication, which bore the self-explanatory title 'Calorie for calorie', dietary fat restriction results in more body fat loss than carbohydrate restriction.

In 2012, Hu et al. published a meta-analysis of randomized controlled clinical studies on the effects of diets containing $<45$ en $\%$ carbohydrates compared to diets that contained less than $30 \mathrm{en} \%$ of fat [40]. This meta-analysis also mapped the risk factors to metabolic processes. Data from 23 studies from various countries, with a total of 2788 participants (study duration of 6-24 months, including 6 studies of 15-24 months), met the inclusion criteria and were included in the analysis. Both the low-carbohydrate diet and the low-fat diet resulted in a decrease in body weight and an improvement of metabolic risk factors. The two groups showed no significant divergences in terms of decrease of body weight, waist circumference and metabolic risk factors. The authors claim that these findings suggest that low-carbohydrate and low-fat diets 
have similar effects on body weight reduction and related risk factors for diseases.

A recent meta-analysis by Mansoor et al. [49] concerned data of 11 randomized controlled studies (total of 1369 participants). The study revealed that participants experienced a greater decrease in body weight and of plasma triglycerides when being on a LCHF diet. However, an increase in LDL cholesterol was also observed, which is in line with the earlier observations of [50]. It has been questioned whether the overall benefits observed do outweigh that of an unfavorable LDL increase [51].

\section{Is a LCHF diet healthy and safe?}

Many food authorities recommend relatively high-carbohydrate and high-fiber intakes as being healthy [52]. Seen in the recommendations, discussed above, the question is what the long-term health implications of LCHF diets would be, given the relatively short duration of virtually all available studies [53, 54]. The limited literature, in which LCHF studies were compared to relatively high-carbohydrate studies, does not show consistent differences in effects on body weight. The only way to get an answer to this question would be to conduct robustly controlled long-term studies (minimum of 2 years) in which carbohydrate, fat, energy and dietary fiber intake are carefully monitored along with changes in body weight. Such studies are hard to carry out and are costly and for that reason have as yet not been carried out. One study that did conduct an evaluation of this issue, and was subject to strict controls, albeit also with a relative short duration of 8 weeks [55], resulted in the conclusion that under conditions of a steady level of energy intake during a hypocaloric diet (- $500 \mathrm{kcal} /$ day) a LCHF diet is just as effective as a low-fat high-carbohydrate diet. In this study weight loss was significant in both groups and improvements in insulin sensitivity were also similar. This is a strong indication that LCHF effects are primarily related to weight loss and corresponding changes to central body fat and the associated metabolic processes.

Two reviews drew the conclusion that the short-term effects of LCHF diets are positive on weight loss and blood glucose management, but also that the long-term effects have not been studied $[11,56]$. The authors indicate that observed effects seemed primarily to relate to weight loss and that, for that reason, the effect of changes in the intake of carbohydrates and fats remained "unclear". Brinkworth et al. [57] concluded that a combination of a low-carbohydrate diet combined with a restriction of energy intake would, due to reductions of fiber intake, lead to adverse effects on the quality of bowel movements and the production of short-chain fatty acids by the flora of the large intestine. They claim that it seems as if this may potentially lead to bowel disease in the long term. After a systematic review and meta-analysis Naude et al. [58] concluded that here is probably little or no difference in weight loss and changes in cardiovascular risk factors up to 2 years of follow-up when overweight and obese adults, with or without type 2 diabetes, are randomized to low $\mathrm{CHO}$ diets and iso-energetic-balanced weight loss diets. In a more recent review, bearing the title "Low-carbohydrate diets and type-2 diabetes: the current status of the evidence", in the journal Diabetes Therapy, Dyson expressed that the state of affairs has not changed much [59]. He concluded that low-carbohydrate diets for people with type-2 diabetes could in the short-term lead to an improvement in blood glucose regulation, weight loss, and reduction of cardiovascular risk factors, but that this appeared no longer to be the case in the longer term. Overall, LCHF diets did not seem to show any superiority compared to diets with a higher carbohydrate intake. On the basis of these findings, he concludes that low-carbohydrate diets are indeed safe in the short term and are effective, but that there are no statistical differences compared with diets containing a higher carbohydrate content. For this reason, Dyson suggests that an LCHF diet should not be recommended as the standard treatment of people with type-2 diabetes [59]. This view is supported by Wyk et al. [31] who describe that "total energy intake remains the best predictor of changes in body weight. A low-carbohydrate diet, in terms of metabolic indicators and blood glucose response, does not differ a great deal from a diet with the usual amount of carbohydrates". Very low-carbohydrate diets seems to score slightly better in this regard, but are harder to adhere to over a longer period of time (more than 6 months). Daily carbohydrate intake, for example, seemed to amount to $132-162 \mathrm{~g}$ per day, despite over a year of dieting and a guiding principle of less than $50 \mathrm{~g}$ per day. The foregoing also implies that there is still a lack of clarity regarding the long-term effects of an LCHF diet on both effectiveness as well as food safety.

The observations of Noto et al. [60] are also relevant in this regard. These authors assessed the effects of lowcarbohydrate diets on probability of mortality, by way of a systematic review and a meta-analysis of the available observational studies. 17 studies were included in total, containing the data of 272,216 people of which 15,981 (5.9\%) were reported dead. The results showed that the risk of mortality under conditions of LCHF diets was significantly higher. In accordance with these findings, many insiders feel that an LCHF diet should only be recommended for persons suffering from overweight and pre-diabetes or type- 2 diabetes, for the reduction of bodyweight and hyperglycemia risks. They recommend that the diet only be followed under strict medical and nutritional supervision. 
Regarding the question whether long-term LCHF diets may pose health risks it should also be noted that a series of recent animal experiments and human studies into the effects of an LCHF diet, for example, show adverse effects in cholesterol, homocysteine, vascular elasticity parameters have been observed during LCHF, indicating that any potential adverse long-term effects of an LCHF vascular health cannot be ruled out [29, 40, 49, 51].

In addition, adverse effects as result of high-fat exposure were reported in the following areas: brain, cognition, memory, mental well-being, Alzheimer's, autistic behaviour [33, 34, 61-63]; obesity, metabolic dysfunction, inflammation, liver damage, cardiometabolic risks' [34, 38, 64-68]; risks of cancer [66, 69]; osteoporosis [70]. In elegant animal models, Cani et al. [71] clearly demonstrated that high fat feeding, which induces low intakes of fermentable dietary fibers, may lead to intestinal microbiota changes which are associated with an increased intestinal permeability resulting in endotoxemia and triggers for inflammation and metabolic disorders (note: the examples are only given as an illustration, not for an exhaustive picture). These data point to possible long-term negative effects on health that should be addressed in future studies.

\section{LCHF for specific patient groups}

Within this context, it should be noted that a KetogenicLCHF (KLCHF) diet is used for specific pathologies such as epilepsy and autism epilepsy and that positive effects have been documented to decrease epileptic seizures. Similarly in this instance, this is also paired with adverse side effects; in addition, the long-term effects on overall health are unknown. Following a robust Cochrane meta-analysis, for example, Martin et al. [72] concluded that randomized, controlled KLCHF studies showed promising results following application in epilepsy patients, but that the limited number of studies, small samples, and one-sided data from child populations, resulted in poor evidential quality. Within all KLCHF studies, short-term side effects were recorded such as gastrointestinal disorders, and cardiovascular complications in the longer term. For all KLCHF studies, "compliance" was a problem due to the lack of effectiveness and/or problematic diet tolerance. The authors believe that there is a lack of evidence to support a clinical application of KLCHF in adults with epilepsy.

\section{New insights?}

A very recent overview [73] concerned randomized intervention studies, with control group, carried out between 2001 and 2015. The authors concluded as follows: a slight though significant decrease of glycated hemoglobin (HbA1c) entails a restriction of carbohydrates $(\mathrm{CH})$ at all levels: $2.2 \%$ at $30 \mathrm{~g} \mathrm{CH} /$ day, $-0.7 \%$ at $\leq 75 \mathrm{CH} /$ day, $-1.1 \%$ at $80-90 \mathrm{~g} \mathrm{CH} /$ day and $-0.9 \%$ with $\mathrm{CH}$ intake to $120 \mathrm{~g} /$ day (a logical consequence of less glucose supply to the blood, under conditions of insulin resistance) [73]. The fasting blood values and the required medication, as such, were lower which resulted in people feeling "better". At an intake of $58 \%$ fat and $14 \%$ carbohydrates, compared with $30 \%$ fat and $53 \%$ carbohydrates, blood triglycerides decreased and HDL cholesterol increased. Decreases in body weight varied from -8.6 to $0.9 \mathrm{~kg}$, with slightly more weight loss in favor of greater carbohydrate restriction. This study, therefore, shows favorable effects in diabetes patients following a controlled LCHF diet lasting to a maximum of $\approx 2$ years. To ensure the correct interpretation of this data, it should be noted that only an abstract was published and that this abstract also contains citations that lead to further questions. We must wait for the comprehensive peer reviewed publication before we can make definitive statements on this matter.

Recent work addressed the potential effectiveness of diets differing in the contents of carbohydrate and fat on weightloss, in dependence of insulinemic and glycemic status and sheds a differentiating light on the question about which diet type may be most effective to lose weight. Hjorth et al. [74] re-evaluated the effects of diets with different glycemic loads or different fiber and whole-grain content as assessed in three large randomized trials in overweight participants (1: the DiOGenes-Diet, Obesity, and Genes study, 2: the OPUSNew Nordic Diet study and 3: the NUGENOB-NutrientGene Interactions in Human Obesity-study). Effects on the concentrations of fasting plasma glucose (FPG) and fasting insulin (FI) as possible prognostic markers for successful weight loss and weight maintenance were determined. It was observed that pre-diabetic (elevated FPG) and diabetic individuals lost more weight or regained less weight when consuming a high-fat and low-carbohydrate diet than when consuming a low-fat and high-carbohydrate diet. On the contrary, in insulin-sensitive individuals, expressing normoglycemia, beneficial effects observed were favorable when consuming a low-fat and relatively high-carbohydrate diet. Wan 2017 observed that a relatively high carbohydrate was effective for weight loss in healthy obese individuals. Based on this data, [75] concluded that disturbed insulin sensitivity and elevated FPG are important determinants for the dietary treatment of choice, being either low fat-high carbohydrate or alternatively, low carbohydrate-high fat. Accordingly, they proposed that stratifying patients for personalized dietary guidance based on pre-diet FPG outcomes may be recommendable. In another paper, however, by Snorgaard and Astrup et al. [14, 76], the same author concluded as follows: "in addition to improvements in $\mathrm{HbAlc}$ in the short term, 
there is no superiority of low-carbohydrate diets in the field of glycemic control, weight or LDL cholesterol.

Based on these observations and the seemingly conflicting conclusions, there is a need for controlled studies, "with intention to treat", to verify these effects as a base for future evidence-based dietary recommendations.

\section{Is life style intervention the favorable way to go?}

Based on the information presented above, it cannot be concluded that LCHF diets result in favorable effects that outweigh effects observed with less-drastic diet regimen, containing more carbohydrate quantities that are closer to daily practise.

One might argue that an improvement of the daily diet is relatively easy to achieve and also effective for disease prevention. Recent expert panels, including those of the WHO [5], the Dutch Health Council [2], the German Food Council [1], Nordic Dietary Recommendations (Scandinavian countries) [77], and the Scientific Advisory Committee on Nutrition in England [3], have concluded that diets rich in fruit, vegetables, cereals, legumes, but also moderately rich in fat and calories, combined with a sufficient amount of daily physical activity constitute the best scenario for maintaining a healthy body weight and for the prevention of chronic lifestyle diseases. This also entails moderation of (added/free) sugar intake and selecting whole-wheat products over low-fiber starch products. The quantity of fat that is unanimously recommended by all these advisory bodies is less than $40 \%$ of daily energy intake. The recommended quantity of carbohydrates for each of these advisory bodies and others [52] is over $40 \%$ of energy intake, which corresponds to more than $180 \mathrm{~g}$ of carbohydrates per day.

In addition to this, it is important to notice that lifestyle interventions that also focus on other factors than diet alone have been shown to result is long-term benefits. Lindström et al. [78] described long-term effects of lifestyle intervention in a Finnish population. The specific intervention goals were weight reduction (5\% or more from baseline weight), dietary modification [energy proportion of total fat less than $30 \%$ and saturated fat less than $10 \%$ of total energy, dietary fiber intake $3.6 \mathrm{~g} / \mathrm{MJ}$ $(15 \mathrm{~g} / 1000 \mathrm{kcal})]$ or more and increased physical activity ( $4 \mathrm{~h}$ per week or more). The authors showed that lifestyle intervention while being on a relative carbohydrate-rich diet in people at high risk of type 2 diabetes induces sustaining lifestyle change and results in long-term prevention of progression to type 2 diabetes. Schellenberg et al. [79] performed a meta-analysis of lifestyle programs and concluded that interventions that include exercise, dietary changes, and at least one other component are effective in decreasing the incidence of type 2 diabetes in high-risk patients, and the benefit extends beyond the active intervention phase. However, in patients who have already been diagnosed with type 2 diabetes, the evidence for benefit of comprehensive lifestyle interventions on patient-oriented outcomes was less clear.

\section{Key points}

1. Each type of diet that results overweight-diabetic individuals to eat less food and taking in less energy will initially result in weight loss, which in itself will lead to favorable metabolic and functional changes.

2. The available scientific literature shows that controlled diet studies (several weeks to $<2$ year) with LCHF in persons with obesity and diabetes do induce favorable effects on weight loss, blood glucose and insulin as well as some less desirable effects (increase LDL cholesterol, decrease vascular reactivity).

3. Compliance with KLCHF diets appears to be poor and after some time many individuals appear to shift to higher intakes in the range of 130-160 g/day. Accordingly, targeting 100-150 g/day may be better achievable.

4. There is lack of data supporting long-term efficacy, safety and health benefits of LCHF diets. Any recommendation should be judged in this light.

5. Persons with type 2 diabetes or borderline diabetes are recommended to restrict their daily intake of rapidly digestible carbohydrates (sugars, syrups, potato, white rice, white bread, etc.). In addition, it is recommended that when switching to a diet that includes a higher portion of fat, people should primarily select products that are rich in unsaturated fatty acids.

6. Lifestyle interventions in people at high risk of developing type 2 diabetes, while maintaining a relative carbohydrate-rich diet, results in long-term prevention of progression to type 2 diabetes and are generally seen as safe.

7. Due to the complexity of the potential mechanisms, their interactions, and an absence of data from robustly controlled long-term studies ( $>2$ years), a general public evidence based recommendation to support KLCHF and LCHF diets as a preventive measure to help reduce risks of type 2 diabetes, seems premature. The role of long-term elevated consumption of fat combined with low-carbohydrate consumption warrants further study before general recommendations can be made.

Acknowledgements The base paper preceding this publication was critically reviewed and by Prof. Dr. Ellen Blaak, Professor of Physiology of Fat Metabolism (Maastricht University, The Netherlands) and Prof. Dr. Henk Bilo, Professor of Internal Medicine, diabetes 
(University of Groningen, The Netherlands). I am grateful for their comments and suggestions.

\section{Compliance with ethical standards}

Conflict of interest This publication has been made WITHOUT any involvement of the Food Industry. The sole intention of the author is to help create transparency to the academia, public, industry and policymakers on truthful interpretation of science. The opinions expressed are based on current scientific evidence as available in scientific journals and publicly accessible. The author has no conflicts of interest.

Open Access This article is distributed under the terms of the Creative Commons Attribution 4.0 International License (http://creativeco mmons.org/licenses/by/4.0/), which permits unrestricted use, distribution, and reproduction in any medium, provided you give appropriate credit to the original author(s) and the source, provide a link to the Creative Commons license, and indicate if changes were made.

\section{References}

1. Hauner H, Bechthold A, Boeing H, Brönstrup A, Buyken A, Leschik-Bonnet E, Linseisen J, Schulze M, Strohm D, Wolfram G (2012) Evidence-based guideline of the German Nutrition Society: carbohydrate intake and prevention of nutrition-related diseases. Ann Nutr Metab 60(Suppl. 1):1-58

2. Gezondheidsraad (2015) Richtlijnen goede voeding 2015. http:// www.erasmusage.com/wp-content/uploads/2015/11/201524_richt lijnen_goede_voeding_2015.pdf. Accessed May 2017

3. Nutrition SACo (2015) Carbohydrates and health. https://www. gov.uk/government/uploads/system/uploads/attachment_data/ file/445503/SACN_Carbohydrates_and_Health.pdf. Accessed May 2017

4. World Health Organization (2015) Guideline: sugars intake for adults and children. World Health Organization. http://apps.who. int/iris/bitstream/10665/149782/1/9789241549028_eng.pdf. Accessed May 2017

5. World Health Organization (2015) Global status report on noncommunicable diseases, 2014: attaining the nine global noncommunicable diseases targets; a shared responsibility. World Health Organization, Geneva. http://apps.who.int/iris/bitstream/10665 /148114/1/9789241564854_eng.pdf?ua=1. Accessed May 2017

6. Amine E, Baba N, Belhadj M, Deurenbery-Yap M, Djazayery A, Forrester T, Galuska D, Herman S, James W, MBuyamba J (2002) Diet, nutrition and the prevention of chronic diseases: report of a Joint WHO/FAO Expert Consultation. World Health Organization. http://www.who.int/dietphysicalactivity/publications/trs91 6/en/gsfao_introduction.pdf. Accessed May 2017

7. DeSalvo KB, Olson R, Casavale KO (2016) Dietary guidelines for Americans. JAMA 315(5):457-458

8. Atkins RD (2002) Dr. Atkins' new diet revolution. Government Institutes. https://shop.atkins.com/Books/c/Atkins@Books. Accessed May 2017

9. Sears B (1991) The zone diet. http://www.zonediet.com. Accessed May 2017

10. Agatston A (2001) The South Beach Diet. http://www.southbeach diet.com. Accessed May 2017

11. Adam-Perrot A, Clifton P, Brouns F (2006) Low-carbohydrate diets: nutritional and physiological aspects. Obes Rev 7(1):49-58

12. McDonald L (1998) The ketogenic diet: a complete guide for the dieter and practitioner. Lyle McDonald. http://biblioteca.usv.ro/ Carti/Nutrition/The\%20Ketogenic\%20Diet-\%20A\%20Complete
\%20Guide\%20For\%20Practitioner\%20McDonald\%200-323x.pdf. Accessed May 2017

13. Volek JS, Fernandez ML, Feinman RD, Phinney SD (2008) Dietary carbohydrate restriction induces a unique metabolic state positively affecting atherogenic dyslipidemia, fatty acid partitioning, and metabolic syndrome. Prog Lipid Res 47(5):307-318

14. Feinman RD, Pogozelski WK, Astrup A, Bernstein RK, Fine EJ, Westman EC, Accurso A, Frassetto L, Gower BA, McFarlane SI (2015) Dietary carbohydrate restriction as the first approach in diabetes management: critical review and evidence base. Nutrition 31(1):1-13

15. Barnard ND, Scialli AR, Turner-McGrievy G, Lanou AJ, Glass J (2005) The effects of a low-fat, plant-based dietary intervention on body weight, metabolism, and insulin sensitivity. Am J Med 118(9):991-997

16. Barnard ND, Cohen J, Jenkins DJ, Turner-McGrievy G, Gloede L, Jaster B, Seidl K, Green AA, Talpers S (2006) A low-fat vegan diet improves glycemic control and cardiovascular risk factors in a randomized clinical trial in individuals with type 2 diabetes. Diabetes Care 29(8):1777-1783

17. Barnard ND, Gloede L, Cohen J, Jenkins DJ, Turner-McGrievy G, Green AA, Ferdowsian H (2009) A low-fat vegan diet elicits greater macronutrient changes, but is comparable in adherence and acceptability, compared with a more conventional diabetes diet among individuals with type 2 diabetes. J Am Diet Assoc 109(2):263-272

18. Jenkins DJ, Kendall CW, Marchie A, Jenkins AL, Augustin LS, Ludwig DS, Barnard ND, Anderson JW (2003) Type 2 diabetes and the vegetarian diet. Am J Clin Nutr 78(3):610S-616S

19. Satija A, Bhupathiraju SN, Rimm EB, Spiegelman D, Chiuve SE, Borgi L, Willett WC, Manson JE, Sun Q, Hu FB (2016) Plantbased dietary patterns and incidence of type 2 diabetes in US men and women: results from three prospective cohort studies. PLoS Med 13(6): 1002039

20. Huang R-Y, Huang C-C, Hu FB, Chavarro JE (2016) Vegetarian diets and weight reduction: a meta-analysis of randomized controlled trials. J Gen Intern Med 31(1):109-116

21. Derbyshire EJ (2016) Flexitarian diets and health: a review of the evidence-based literature. Front Nutr 3:55. https://doi. org/10.3389/fnut.2016.00055

22. Willcox DC, Scapagnini G, Willcox BJ (2014) Healthy aging diets other than the Mediterranean: a focus on the Okinawan diet. Mech Ageing Dev 136:148-162

23. Noakes T (2014) Medical aspects of the low carbohydrate lifestyle. https://www.youtube.com/watch?v=fL5-9ZxamXc. Accessed May 2017

24. Eaton SB (2006) The ancestral human diet: what was it and should it be a paradigm for contemporary nutrition? Proc Nutr Soc 65(01):1-6

25. Raubenheimer D, Rothman JM, Pontzer H, Simpson SJ (2014) Macronutrient contributions of insects to the diets of hunter-gatherers: a geometric analysis. J Hum Evol 71:70-76

26. Eaton SB, Eaton SR, Konner MJ (1997) Paleolithic nutrition revisited: a twelve-year retrospective on its nature and implications. Eur J Clin Nutr 51(4):207-216

27. Kaplan H, Thompson RC, Trumble BC, Wann LS, Allam AH, Beheim B, Frohlich B, Sutherland ML, Sutherland JD, Stieglitz J (2017) Coronary atherosclerosis in indigenous South American Tsimane: a cross-sectional cohort study. Lancet 389(10080):1730-1739

28. Van Rossum C, Fransen H, Verkaik-Kloosterman J, BuurmaRethans E, Ocké M (2011) Dutch National Food Consumption Survey 2007-2010: diet of children and adults aged 7 to 69 years. RIVM rapport 350050006

29. Westman EC, Feinman RD, Mavropoulos JC, Vernon MC, Volek JS, Wortman JA, Yancy WS, Phinney SD (2007) 
Low-carbohydrate nutrition and metabolism. Am J Clin Nutr 86(2):276-284

30. VanItallie TB, Nufert TH (2003) Ketones: metabolism's ugly duckling. Nutr Rev 61(10):327-341

31. Wyk H, Davis R, Davies J (2016) A critical review of lowcarbohydrate diets in people with type 2 diabetes. Diabet Med 33(2):148-157

32. Hall K (2017) A review of the carbohydrate-insulin model of obesity. http://undark.org/wp-content/uploads/sites/2/2017/02/ HallEJCN2017-1.pdf. Accessed May 2017

33. Vinuesa A, Pomilio C, Menafra M, Bonaventura MM, Garay L, Mercogliano MF, Schillaci R, Lantos VL, Brites F, Beauquis J (2016) Juvenile exposure to a high fat diet promotes behavioral and limbic alterations in the absence of obesity. Psychoneuroendocrinology 72:22-33

34. Walker JM, Dixit S, Saulsberry AC, May JM, Harrison FE (2017) Reversal of high fat diet-induced obesity improves glucose tolerance, inflammatory response, $\beta$-amyloid accumulation and $\operatorname{cog}$ nitive decline in the APP/PSEN1 mouse model of Alzheimer's disease. Neurobiol Dis 100:87-98

35. King M (2017) Gluconeogenesis: endogenous glucose synthesis. https://themedicalbiochemistrypage.org/gluconeogenesis.php. Accessed May 2017

36. Belkhou R, Cherel Y, Heitz A, Robin J-P, Le Maho Y (1991) Energy contribution of proteins and lipids during prolonged fasting in the rat. Nutr Res 11(4):365-374

37. Rui L (2014) Energy metabolism in the liver. Compr Physiol 4(1):177-197. https://doi.org/10.1002/cphy.c130024

38. Yamazaki T, Okawa S, Takahashi M (2016) The effects on weight loss and gene expression in adipose and hepatic tissues of verylow carbohydrate and low-fat isoenergetic diets in diet-induced obese mice. Nutr Metab 13(1):78

39. Accurso A, Bernstein RK, Dahlqvist A, Draznin B, Feinman RD, Fine EJ, Gleed A, Jacobs DB, Larson G, Lustig RH (2008) Dietary carbohydrate restriction in type 2 diabetes mellitus and metabolic syndrome: time for a critical appraisal. Nutr Metab 5(1):9

40. Hu T, Mills KT, Yao L, Demanelis K, Eloustaz M, Yancy WS Jr, Kelly TN, He J, Bazzano LA (2012) Effects of low-carbohydrate diets versus low-fat diets on metabolic risk factors: a metaanalysis of randomized controlled clinical trials. Am J Epidemiol 176(suppl_7):S44-SS54

41. Kennedy ET, Bowman SA, Spence JT, Freedman M, King J (2001) Popular diets: correlation to health, nutrition, and obesity. J Acad Nutr Diet 101(4):411

42. U.S. Department of Agriculture ARS (1998) Data tables: food and nutrient intakes by region, 1994-96. http://www.barc.usda. gov/bhnrc/foodsurvey/home.htm. Accessed May 2017

43. Aune D, Keum N, Giovannucci E, Fadnes LT, Boffetta P, Greenwood DC, Tonstad S, Vatten LJ, Riboli E, Norat T (2016) Whole grain consumption and risk of cardiovascular disease, cancer, and all cause and cause specific mortality: systematic review and doseresponse meta-analysis of prospective studies. BMJ 353:i2716

44. Ma X, Tang W-G, Yang Y, Zhang Q-L, Zheng J-L, Xiang Y-B (2016) Association between whole grain intake and all-cause mortality: a meta-analysis of cohort studies. Oncotarget 7(38):61996

45. Albertson AM, Reicks M, Joshi N, Gugger CK (2016) Whole grain consumption trends and associations with body weight measures in the United States: results from the cross sectional National Health and Nutrition Examination Survey 2001-2012. Nutr J 15(1):8

46. Vanegas SM, Meydani M, Barnett JB, Goldin B, Kane A, Rasmussen H, Brown C, Vangay P, Knights D, Jonnalagadda S (2017) Substituting whole grains for refined grains in a 6-wk randomized trial has a modest effect on gut microbiota and immune and inflammatory markers of healthy adults. Am J Clin Nutr 105(3):635-650
47. Astrup A, Grunwald G, Melanson E, Saris W, Hill J (2000) The role of low-fat diets in body weight control: a meta-analysis of ad libitum dietary intervention studies. Int J Obes 24(12): 1545

48. Hall KD, Bemis T, Brychta R, Chen KY, Courville A, Crayner EJ, Goodwin S, Guo J, Howard L, Knuth ND (2015) Calorie for calorie, dietary fat restriction results in more body fat loss than carbohydrate restriction in people with obesity. Cell Metab 22(3):427-436

49. Mansoor N, Vinknes KJ, Veierød MB, Retterst $\varnothing 1$ K (2016) Effects of low-carbohydrate diets v. low-fat diets on body weight and cardiovascular risk factors: a meta-analysis of randomised controlled trials. Br J Nutr 115(03):466-479

50. Nordmann AJ, Nordmann A, Briel M, Keller U, Yancy WS, Brehm BJ, Bucher HC (2006) Effects of low-carbohydrate vs low-fat diets on weight loss and cardiovascular risk factors: a meta-analysis of randomized controlled trials. Arch Intern Med 166(3):285-293

51. Wood TR, Hansen R, Sigurðsson AF, Jóhannsson GF (2016) The cardiovascular risk reduction benefits of a low-carbohydrate diet outweigh the potential increase in LDL-cholesterol. Br J Nutr 115(6): 1126

52. Buyken AE, Dussort DJM,P, Johnson IT, Macdonald IA, Stowell JD, Brouns FJPH. (2017) Dietary carbohydrates: a review of international recommendations and the methods used to derive them. Eur J Clin Nutr. https://doi.org/10.1038/s41430-017-0035-4. (in press)

53. Stern L, Iqbal N, Seshadri P, Chicano KL, Daily DA, McGrory J, Williams M, Gracely EJ, Samaha FF (2004) The effects of lowcarbohydrate versus conventional weight loss diets in severely obese adults: one-year follow-up of a randomized trial. Ann Intern Med 140(10):778-785

54. Foster GD, Wyatt HR, Hill JO, McGuckin BG, Brill C, Mohammed BS, Szapary PO, Rader DJ, Edman JS, Klein S (2003) A randomized trial of a low-carbohydrate diet for obesity. N Engl J Med 348(21):2082-2090

55. Bradley U, Spence M, Courtney CH, McKinley MC, Ennis CN, McCance DR, McEneny J, Bell PM, Young IS, Hunter SJ (2009) Low-fat versus low-carbohydrate weight reduction diets. Diabetes 58(12):2741-2748

56. Bilsborough SA, Crowe T (2003) Low carbohydrate diets: what are the potential short and long term health implications? Asia Pac J Clin Nutr 12(4):397-404

57. Brinkworth GD, Noakes M, Clifton PM, Bird AR (2009) Comparative effects of very low-carbohydrate, high-fat and highcarbohydrate, low-fat weight-loss diets on bowel habit and faecal short-chain fatty acids and bacterial populations. Br J Nutr 101(10):1493-1502

58. Naude CE, Schoonees A, Senekal M, Young T, Garner P, Volmink J (2014) Low carbohydrate versus isoenergetic balanced diets for reducing weight and cardiovascular risk: a systematic review and meta-analysis. PLoS One 9(7):e100652

59. Dyson $P$ (2015) Low carbohydrate diets and type 2 diabetes: what is the latest evidence? Diabetes Therapy 6(4):411-424

60. Noto H, Goto A, Tsujimoto T, Noda M (2013) Low-carbohydrate diets and all-cause mortality: a systematic review and meta-analysis of observational studies. PLoS One 8(1):e55030

61. Zilkha N, Kuperman Y, Kimchi T (2017) High-fat diet exacerbates cognitive rigidity and social deficiency in the BTBR mouse model of autism. Neuroscience 345:142-154

62. Raider K, Ma D, Harris JL, Fuentes I, Rogers RS, Wheatley JL, Geiger PC, Yeh H-W, Choi I-Y, Brooks WM (2016) A high fat diet alters metabolic and bioenergetic function in the brain: a magnetic resonance spectroscopy study. Neurochem Int 97:172-180

63. Del Rio D, Morales L, Ruiz-Gayo M, Del Olmo N (2016) Effect of high-fat diets on mood and learning performance in adolescent mice. Behav Brain Res 311:167-172 
64. Wang W, Yang J, Yang H, Sanidad KZ, Hammock BD, Kim D, Zhang G (2016) Effects of high-fat diet on plasma profiles of eicosanoid metabolites in mice. Prostaglandins Other Lipid Mediat 127:9-13

65. Long Z, Zhang X, Sun Q, Liu Y, Liao N, Wu H, Wang X, Hai C (2017) Evolution of metabolic disorder in rats fed high sucrose or high fat diet: focus on redox state and mitochondrial function. Gen Comp Endocrinol 242:92-100. https://doi.org/10.1016/j. ygcen.2015.10.012

66. O'Neill AM, Burrington CM, Gillaspie EA, Lynch DT, Horsman MJ, Greene MW (2016) High-fat Western diet-induced obesity contributes to increased tumor growth in mouse models of human colon cancer. Nutr Res 36(12):1325-1334

67. Moon C-M, Oh C-H, Ahn K-Y, Yang J-S, Kim J-Y, Shin S-S, Lim H-S, Heo S-H, Seon H-J, Kim J-W (2017) Metabolic biomarkers for non-alcoholic fatty liver disease induced by high-fat diet: In vivo magnetic resonance spectroscopy of hyperpolarized [1-13 C] pyruvate. Biochem Biophys Res Commun 482(1):112-119

68. Kai M, Miyoshi M, Fujiwara M, Nishiyama Y, Inoue T, Maeshige N, Hamada Y, Usami M (2017) A lard-rich high-fat diet increases hepatic peroxisome proliferator-activated receptors in endotoxemic rats. J Surg Res 212:22-32

69. Xia S, Lin R, Jin L, Zhao L, Kang HB, Pan Y, Liu S, Qian G, Qian Z, Konstantakou E, Zhang B, Dong JT, Chung YR, Abdel-Wahab O, Merghoub T, Zhou L, Kudchadkar RR, Lawson DH, Khoury HJ, Khuri FR, Boise LH, Lonial S, Lee BH, Pollack BP, Arbiser JL, Fan J, Lei QY, Chen J (2017) Prevention of dietary-fat-fueled ketogenesis attenuates BRAF V600E tumor growth. Cell Metab 25(2):358-373. https://doi.org/10.1016/j.cmet.2016.12.010

70. Yamasaki M, Hasegawa S, Imai M, Takahashi N, Fukui T (2016) High-fat diet-induced obesity stimulates ketone body utilization in osteoclasts of the mouse bone. Biochem Biophys Res Commun 473(2):654-661

71. Cani PD, Bibiloni R, Knauf C, Waget A, Neyrinck AM, Delzenne NM, Burcelin R (2008) Changes in gut microbiota control metabolic endotoxemia-induced inflammation in high-fat dietinduced obesity and diabetes in mice. Diabetes 57(6):1470-1481. https://doi.org/10.2337/db07-1403

72. Martin K, Jackson CF, Levy RG, Cooper PN (2016) Ketogenic diet and other dietary treatments for epilepsy. Cochrane Database Syst Rev 2:CD001903. https://doi.org/10.1002/14651858.CD001 903.pub3

73. McKenzie M, Illingworth S (2017) Should a low carbohydrate diet be recommended for diabetes management? Proc Nutr Soc 76 (OCE1). https://doi.org/10.1017/S0029665117000192

74. Hjorth MF, Ritz C, Blaak EE, Saris WH, Langin D, Poulsen SK, Larsen TM, Sørensen TI, Zohar Y, Astrup A (2017) Pretreatment fasting plasma glucose and insulin modify dietary weight loss success: results from 3 randomized clinical trials. Am J Clin Nutr 106(2):499-505

75. Astrup A, Hjorth MF (2017) Low-fat or low carb for weight loss? It depends on your glucose metabolism. EBioMedicine 22:20

76. Snorgaard O, Poulsen GM, Andersen HK, Astrup A (2017) Systematic review and meta-analysis of dietary carbohydrate restriction in patients with type 2 diabetes. BMJ Open Diabetes Res Care 5(1):e000354

77. Mithril C, Dragsted LO, Meyer C, Blauert E, Holt MK, Astrup A (2012) Guidelines for the new Nordic diet. Public Health Nutr 15(10):1941-1947

78. Lindström J, Peltonen M, Eriksson J, Ilanne-Parikka P, Aunola S, Keinänen-Kiukaanniemi S, Uusitupa M, Tuomilehto J, Study FDP (2013) Improved lifestyle and decreased diabetes risk over 13 years: long-term follow-up of the randomised Finnish Diabetes Prevention Study (DPS). Diabetologia 56(2):284-293

79. Schellenberg ES, Dryden DM, Vandermeer B, Ha C, Korownyk C (2013) Lifestyle interventions for patients with and at risk for type 2 diabetes-a systematic review and meta-analysis. Ann Intern Med 159(8):543-551 